\title{
Defining a Critical Mass Threshold for Agricultural Support Services
}

\author{
Aaron J. Nousaine (Corresponding author) \\ Center for Competitive Economies, University of North Carolina at Chapel Hill \\ CB\# 3440, Chapel Hill, North Carolina 27599-3440, United States \\ Tel: 1-919-672-3332Ｅ-mail: aaronnousaine@gmail.com \\ G. Jason Jolley \\ The Voinovich School of Leadership and Public Affairs, Ohio University \\ Building 21, 1 Ohio University, Athens, Ohio 45701-2979, United States \\ Tel: 1- 740-593-9797Ｅ-mail: jolleyg1@ohio.edu \\ Received: November 30, 2012 Accepted: December 15, 2012 Published: February 2, 2013 \\ doi:10.5296/jas.v1i1.2779 URL: http://dx.doi.org/10.5296/jas.v1i1.2779
}

\begin{abstract}
Utilizing four counties in western North Carolina as a study area, this paper examines the existence of a critical mass threshold in agricultural production below which crucial support services could be expected to close down or relocate outside the region. Twenty-two key stakeholder interviews suggest that for most support service businesses, no such critical mass threshold exists at the regional level. For those support service types most at-risk, an IMPLAN model was utilized to determine the economic impact to the region.
\end{abstract}

Keywords: critical mass threshold, agriculture support services, economic impact, western North Carolina

\section{Introduction}

The structure of the American agriculture is decidedly changed from that of the previous century. Mechanization and other technological advances have wildly increased the productivity of industrialized operations at the national scale. With downward pressure on commodity prices, incomes to small and medium sized farmers have eroded. Many contemporary family farms now depend on non-farm income to maintain their livelihoods. This decline in the economic viability of lower-intensity agriculture is destabilizing many rural communities. Where small farmers once purchased inputs from local suppliers and sold their products in local or regional markets, the vertical integration of industrial operations are 
closing off important linkages in the agricultural value chain. With dwindling access to critical products and services, smaller farms face increasing costs of production, coupled with suppressed commodity prices, endangering their long-term financial stability.

This paper poses the hypothesis that there is a threshold, or point of critical mass, in agricultural production, below which a variety of businesses, institutions, and supplier networks that provide support services to agriculture, may be expected to close down or relocate outside the region. Using four counties in western North Carolina as a case study, this paper examines the critical mass threshold for agricultural support services necessary to overcome structural barriers and sustain agriculture in this rural region. The research provides local policy makers with evidence for and against the existence of a critical mass threshold and highlights which support service categories may be most at-risk. These techniques, and the challenges faced by western North Carolina, are generalizable to other rural regions, especially those in Appalachia and other mountainous regions.

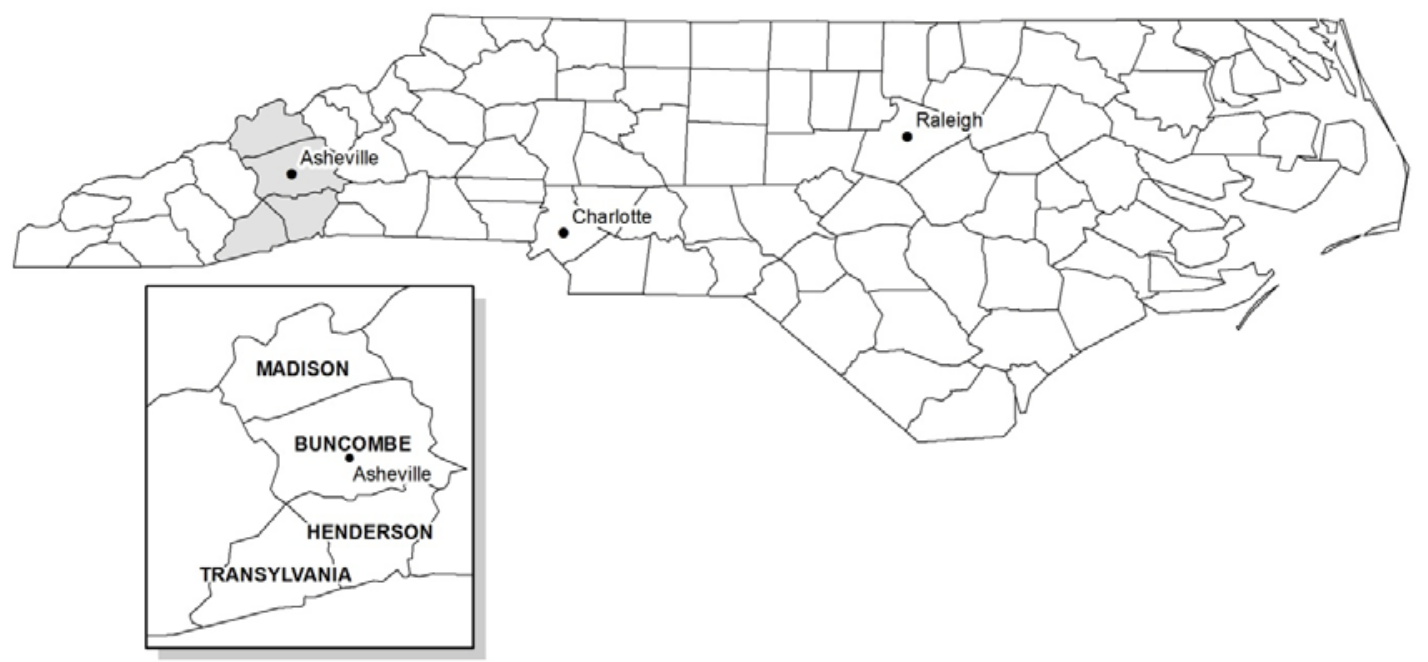

Figure 1. Map of the study area in North Carolina.

The region, in this context, includes the counties of Buncombe, Henderson, Madison, and Transylvania in the western mountains of North Carolina. In western North Carolina, farms are of smaller than average size and face constraints of geography and climate. Steep ridges and narrow valley bottoms limit the cultivatable land area. As a result, many farms achieve subsistence through diversified production; taking advantage of not only the fertile valley floor, but also the grassy slopes for livestock, and timber harvesting on the wooded ridge tops. In the past, the mountainous terrain greatly restricted farmers' access to global markets. With the introduction of the railroad in the 1800's, and development of the Interstate Highways in the late 1950's and 60's, the region is now strategically well situated for the distribution of goods to the highly competitive markets of the Northeast and South. Unfortunately, it appears that the region's limited capacity to produce high volumes of agricultural goods restrict its ability to capitalize on this comparative advantage.

While public programs to retain farm supporting businesses have received substantial focus 
abroad, policies and programs that overcome the structural challenges to small-farm agriculture are far less common in the United States. The Western North Carolina Regional Livestock Center under development in Haywood County is a good example of what these programs can look like. In this case, a local non-profit is financing construction of a new stockyard facility. A for-profit entity will then operate the complex and host a local livestock auction. The intent is to address structural barriers to meat producers, who currently transport their cattle over 65 miles, one-way, to markets in South Carolina and Tennessee. Not only will the new facility reduce transportation costs, organizers anticipate that it will also increase sales income to farmers, since livestock will lose less weight from transportation related stress (Agribusiness Solutions, 2008).

One likely reason more institutions do not pursue these types of market interventions is that farmland preservation and agritourism initiatives cost much less, compared to building new processing, distribution, or sales facilities. Despite this relative lack of domestic attention, economic theory suggests that for those concerned with the long-term economic sustainability of local agriculture, the promotion and maintenance of a viable system of agricultural support products, services, and institutions should remain a core concern. As the economic viability of smaller-scale agricultural production continues to wane, and farmland is irreversibly converted to non-farm uses, we may reach a point at which both agriculture, and its attendant industries, recede beyond the point of recovery.

The desire to both establish the existence of the critical mass threshold, and to estimate its economic implications, required the use of a mixed methodology of qualitative interviews and quantitative economic modeling. The 22 semi-structured interviews conducted for this research provide insight into current trends, forward linkages, and structural shifts that would not otherwise be captured by an input-output analysis. The IMPLAN economic model then leverages inputs developed during the interview phase to estimate the potential magnitude of the impact that these trends might impose on the region's economy.

\section{Literature Review}

Over the last four decades, agriculture in America has undergone a broad restructuring. Within the context of western industrialized farming, production relies heavily on mechanization and the use of petro-chemical fertilizers. With heavy subsidies from federal and state governments, the industry has seen a steady increase in productivity and a tendency toward the concentration of ownership and management (Stull \& Broadway, 2004). Horizontal integration has allowed producers to capitalize on vast economies of scale and exert greater influence over certain parts of the production process. Through vertical integration, firms have acquired control over multiple stages of the value chain, often including cultivation, transportation, storage, processing, and wholesaling. This combined broadening and deepening has resulted in downward pressure on commodity prices, effectively forcing out "inefficient” producers (Perrett, 2007). Fortified by farm policy, the industry has become dominated by fewer but larger farm operations. Today, small and medium sized farms continue to make up over 90 percent of all U.S. farm operations. However, these account for less than 25 percent of the nation's total agricultural output (U.S. 
Department of Agriculture, 2009).

This consolidation not only creates significant price competition for smaller farmers, but manifests in a lack of bargaining power when negotiating contracts with wholesale distributors, packers, and retailers. These actors prefer, most often, to associate with large firms who can offer higher volumes, greater post-harvest services, and more stringent processing standards (Hendrickson, Heffernan, Howard, \& Heffernan, 2001). Reflecting the relative inability of smaller farms to successfully compete alongside large industrial operations is the increase in the proportion of farm households being either partially or mostly supported by off-farm employment. This figure has increased significantly over the years, reaching as high as 93 percent in 2000 (Hoppe \& Banker, 2010; Hoppe, MacDonald \& Korb, 2010; Perrett, 2007; McDonald, Hoppe \& Banker, 2006).

With many agricultural areas facing increasing rates of urbanization and a high degree of speculative land development, many large producers have taken the opportunity to sell their high priced agricultural land in urbanizing or metropolitan areas, using the revenue to out bid smaller scale farmers in more rural locals (Esseks, Oberholtzer, Clancy, Lapping \& Zurbrugg, 2009). Likewise, struggling smaller farmers in urbanizing areas - particularly those with children who do not intend to take up a career in farming - often see the sale of agricultural land to developers as a way to "cash out" from a declining industry (Hoppe \& Banker, 2010; Esseks, et. al., 2009; MacDonald et all, 2006).

As the irreversible loss of agricultural land becomes of greater concern, some have questioned whether a critical mass of farmland or agricultural production is required to maintain the economic viability of the industry (Lapping, 1982). This threshold or "critical mass" concept relies on the assumption that as cultivated acreage and aggregate farm productivity decline, the ratio of costs to revenue will rise, driving support businesses to close or relocate. With suppliers and processors exiting the region, the nearest alternative may be much farther away, adding to the farmers' transportation costs. These other firms may also charge different prices for products and services. These increases in costs, combined with other factors, may significantly impact the competitiveness of regional agriculture, even leading to large-scale collapse. Lynch and Carpenter (2002), for example, analyzed historical data for 1949 to 1997 and found evidence of a higher rate of agricultural land conversion in counties with less than 150,000 acres of farmland. The caveat, however, is that an analysis of only more recent years (1978 to 1997) showed no evidence of a critical mass threshold. This suggests, as the authors note, that technological change and crop diversification may play a role in determining, and possibly overcoming, this threshold effect (Lynch and Carpenter, 2002; 2003).

While the concept of a critical mass threshold for agriculture is not well established in the literature, the importance of critical mass is a key component in the theory of industry clusters. Industry clusters were originally popularized by Michael Porter (1998, 2000, 2003) who's work serves as a common framework for economic development practice in the United States and abroad. Porter (1998) defined clusters as "geographic concentrations of interconnected companies and institutions." Central to clusters is the requirement that a 
critical mass or concentration of firms exist within a strictly defined geographic area. Henry and Drabenstott (1996) found that having "a critical mass of similar firms" or a cluster was an important determinant of rural economic job growth. When a critical mass or cluster of related firms exists, it promotes access to specialized information and supportive service providers that would not be available to individual firms operating in isolation (Porter, 1998). Logically, it follows that as the size of the cluster declines due to technological change or industrial restructuring, then this access to critical information and supportive services would likewise erode. This research extends the concepts of critical mass and clustering by examining how the agricultural support sector might react to declining agricultural productivity, small-farm profitability, continued farmland conversion, and urbanization.

\section{Overview of Agriculture in Western North Carolina}

The first thing to acknowledge is that agriculture in the Land-of- Sky region is very different from agriculture elsewhere in the country. The most prevalent crops include apples, assorted berries, vegetables like peppers and cherry tomatoes, greenhouse grown ornamental flowers and herbs, and various nursery products including trees and landscaping shrubs.

\begin{tabular}{|c|c|c|c|c|c|c|c|c|c|c|}
\hline \multirow[b]{3}{*}{ Commodity Group } & \multicolumn{6}{|c|}{ Land-of-Sky (a) } & \multicolumn{4}{|c|}{ North Carolina } \\
\hline & \multicolumn{3}{|c|}{2002} & \multicolumn{3}{|c|}{2007} & \multicolumn{2}{|c|}{2002} & \multicolumn{2}{|c|}{2007} \\
\hline & $\begin{array}{c}\text { Number } \\
(\$ 1,000)\end{array}$ & & Percent & $\begin{array}{l}\text { Number } \\
(\$ 1,000) \\
\end{array}$ & & Percent & $\begin{array}{l}\text { Number } \\
(\$ 1,000)\end{array}$ & Percent & $\begin{array}{l}\text { Number } \\
(\$ 1,000)\end{array}$ & Percent \\
\hline Corn & n.a. & & n.a. & $\$ 1,141$ & (b) & $1.0 \%$ & n.a. & n.a. & $\$ 347,995$ & $3.4 \%$ \\
\hline Wheat & n.a. & & n.a. & $\$ 0$ & (b) & $0.0 \%$ & n.a. & n.a. & $\$ 96,691$ & $0.9 \%$ \\
\hline Soybeans & n.a. & & n.a. & $\$ 26$ & (b) & $0.0 \%$ & n.a. & n.a. & $\$ 246,716$ & $2.4 \%$ \\
\hline Sorghum & n.a. & & n.a. & $\$ 0$ & (b) & $0.0 \%$ & n.a. & n.a. & $\$ 1,495$ & $0.0 \%$ \\
\hline Barley & n.a. & & n.a. & $\$ 0$ & (b) & $0.0 \%$ & n.a. & n.a. & $\$ 2,273$ & $0.0 \%$ \\
\hline Rice & n.a. & & n.a. & $\$ 0$ & (b) & $0.0 \%$ & n.a. & n.a. & $\$ 0$ & $0.0 \%$ \\
\hline Other Grains, Oilseeds, Dry Beans \& Peas & n.a. & & n.a. & $\$ 0$ & (b) & $0.0 \%$ & n.a. & n.a. & $\$ 2,621$ & $0.0 \%$ \\
\hline Grains, Oilseeds, Dry Beans \& Peas Subtotal & $\$ 849$ & (b) & $0.8 \%$ & $\$ 1,226$ & & $1.0 \%$ & $\$ 359,296$ & $5.2 \%$ & $\$ 697,792$ & $6.8 \%$ \\
\hline Tobacco & $\$ 7,384$ & & $6.7 \%$ & $\$ 1,057$ & & $0.9 \%$ & $\$ 630,397$ & $9.1 \%$ & $\$ 549,636$ & $5.3 \%$ \\
\hline Cotton \& Cottons eed & $\$ 0$ & & $0.0 \%$ & $\$ 0$ & & $0.0 \%$ & $\$ 181,835$ & $2.6 \%$ & $\$ 211,129$ & $2.0 \%$ \\
\hline Vegetable, Mel on, Potato, \& Sweet Potato & $\$ 14,503$ & & $13.2 \%$ & $\$ 5,720$ & (b) & $4.8 \%$ & $\$ 215,247$ & $3.1 \%$ & $\$ 333,939$ & $3.2 \%$ \\
\hline Fruits, Tree Nuts, \& Berries & $\$ 12,476$ & & $11.4 \%$ & $\$ 9,713$ & (b) & $8.1 \%$ & $\$ 55,756$ & $0.8 \%$ & $\$ 79,288$ & $0.8 \%$ \\
\hline Nursery, Greenhouse, Floriculture, \& Sod & $\$ 50,118$ & & $45.7 \%$ & $\$ 7,678$ & (b) & $6.4 \%$ & $\$ 424,478$ & $6.1 \%$ & $\$ 573,529$ & $5.6 \%$ \\
\hline Cut Christmas Trees \& Woody Crops & $\$ 871$ & & $0.8 \%$ & $\$ 423$ & (b) & $0.4 \%$ & $\$ 57,625$ & $0.8 \%$ & $\$ 65,023$ & $0.6 \%$ \\
\hline Other Crops and Hay & $\$ 1,659$ & & $1.5 \%$ & $\$ 852$ & (b) & $0.7 \%$ & $\$ 84,001$ & $1.2 \%$ & $\$ 95,943$ & $0.9 \%$ \\
\hline Other Crops Subtotal & $\$ 87,036$ & & $79 \%$ & $\$ 94,236$ & & $79 \%$ & $\$ 1,649,338$ & $24 \%$ & $\$ 1,908,486$ & $19 \%$ \\
\hline Subtotal All Crops, Except Livestock & $\$ 87,885$ & & $80 \%$ & $\$ 95,462$ & & $80 \%$ & $\$ 2,008,634$ & $29 \%$ & $\$ 2,606,279$ & $25 \%$ \\
\hline Poultry \& Eggs & $\$ 77$ & (b) & $0.1 \%$ & $\$ 376$ & & $0.3 \%$ & $\$ 2,382,365$ & $34.2 \%$ & $\$ 4,087,004$ & $39.6 \%$ \\
\hline Cattle \& Calves & $\$ 6,352$ & & $5.8 \%$ & $\$ 6,495$ & (b) & $5.4 \%$ & $\$ 185,222$ & $2.7 \%$ & $\$ 288,801$ & $2.8 \%$ \\
\hline Milk \& Other Dairy Products from Cows & $\$ 11,074$ & & $10.1 \%$ & $\$ 8,284$ & & $6.9 \%$ & $\$ 150,406$ & $2.2 \%$ & $\$ 161,373$ & $1.6 \%$ \\
\hline Hogs \& Pigs & $\$ 381$ & (b) & $0.0 \%$ & $\$ 96$ & & $0.1 \%$ & $\$ 2,183,646$ & $31.4 \%$ & $\$ 3,104,731$ & $30.1 \%$ \\
\hline Sheep, Goats, \& Their Products & $\$ 253$ & & $0.2 \%$ & $\$ 522$ & & $0.4 \%$ & $\$ 2,960$ & $0.0 \%$ & $\$ 6,632$ & $0.1 \%$ \\
\hline Horses, Ponies, Mules, Burros, \& Donkeys & $\$ 407$ & & $0.4 \%$ & $\$ 831$ & (b) & $0.7 \%$ & $\$ 15,202$ & $0.2 \%$ & $\$ 17,959$ & $0.2 \%$ \\
\hline Aquaculture & $\$ 3,405$ & (b) & $3.1 \%$ & $\$ 3,132$ & (b) & $2.6 \%$ & $\$ 17,669$ & $0.3 \%$ & $\$ 32,175$ & $0.3 \%$ \\
\hline Other Animals \& Other Animal Products & $\$ 53$ & (b) & $0.0 \%$ & $\$ 27$ & (b) & $0.0 \%$ & $\$ 15,581$ & $0.2 \%$ & $\$ 8,676$ & $0.1 \%$ \\
\hline Livestock, Poultry, \& Their Products Subtotal & $\$ 21,729$ & & $20 \%$ & $\$ 24,325$ & & $20 \%$ & $\$ 4,953,052$ & $71 \%$ & $\$ 7,707,350$ & $75 \%$ \\
\hline Total All Commodities (c) & $\$ 109,614$ & & $100 \%$ & $\$ 119,787$ & & $100 \%$ & $\$ 6,961,686$ & $100 \%$ & $\$ 10,313,628$ & $100 \%$ \\
\hline Inflation Adjusted (2007 Dollars) (d) & $\$ 161,612$ & & & $\$ 119,787$ & & & $\$ 10,264,114$ & & $\$ 10,313,628$ & \\
\hline
\end{tabular}

Notes:

(a) The Land-of-Sky Region includes the Counties of Buncombe, Henderson, Madison, and Transylvania.

(b) Excludes data for one or more counties that has been suppressed to prevent disclosure of confidential information.

(c) Figures may not sum to totals due to rounding.

(d) Figures are adjusted for inflation based on the U.S. Department of Agriculture Producer Price Index. 
Table 1 shows a breakdown of crop values by commodity. The most notable feature is the limited production of commodities like corn, wheat, and soybeans. While these crops constitute the core of Midwestern industrialized agriculture, they are almost completely absent from the region, and make up only around seven percent of the state's total output.

The region also appears to go against the dominant trends in North Carolina agriculture with nearly 80 percent of regional output concentrated in the "Other Crops" category, compared to only 19 percent in the state. This category, as alluded to earlier, includes fruits, vegetables, greenhouse, and nursery products. While cattle and dairy production remain an important part of the regional economy, the livestock sector as a whole makes up only around 20 percent of total farm sales. In the state, livestock and poultry sales are a much more important sector at around 75 percent of total farm sales. This is likely attributable to the industrialized hog and poultry raising operations that predominate in the Piedmont and Coastal Plain regions of North Carolina.

Presumably an outgrowth of the region's atypical product mix and constrained geography, the region appears to be relatively less productive in terms of total cash receipts, compared to counties in the eastern portion of the state. Buncombe and Henderson counties received between $\$ 50$ and $\$ 100$ million in total farm sales in 2009. Madison and Transylvania counties, on the other hand, less than $\$ 20$ million. This is contrasted to some of the far eastern counties in the state that received $\$ 200$ million or more in total cash receipts from farm marketings in the same year.

What is most concerning is that the region appears to also be declining in total production value, in real terms, compared to the state. Table 1, in addition to nominal crop values, reports inflation adjusted crop values. According to these figures, the total value of regional farm marketings declined by almost 26 percent between 2002 and 2007. This equals a compound annual rate of decline of 5.8 percent, which can be compared around one percent per year for the state.

One partial explanation for this is the introduction of the federal tobacco buy-out program in 2004. Established under the Fair and Equitable Tobacco Reform Act, the bill ended the Depression-era tobacco quota system that artificially maintained high tobacco prices. Prior to the buy-out, burley tobacco production was an important income source for rural households. Post 2004, production was almost completely abandoned. In 2002, for example, the value of tobacco production in the region equaled almost $\$ 7.4$ million. By 2007, this had fallen to just one million dollars in total value.

The tobacco buy-out, however, is not the only factor contributing to the region's declining productivity. According to Census figures, the rate of agricultural land conversion in the region between 2002 and 2007 was equal to 4.7 percent per year. This is comparable to only around 1.4 percent per year for North Carolina as a whole. Broken down at the county level, one fourth of the region is losing its agricultural land at a rate roughly equal to, or greater than, four percent per year. Transylvania County alone showed a lower rate of two percent per year, reflecting lower development pressures. 
Another factor influencing the conversion of land to non-farm uses is the relatively low average value of farm assets, despite comparatively high per acre land values. Census values for farmland and buildings suggest that the average farm in the region was worth over half a million dollars in 2007. This is roughly $\$ 150,000$ less than in the state as a whole. On a per acre basis, however, farmland in the region averaged around \$7,000, compared to only $\$ 4,000$ in the state. These contradictory valuations are likely symptomatic of three distinct factors. The first is the region's relative shortage of arable land suitable for either cultivation or development. The second is the smaller than average farm size resulting from this inherent land constraint. The third is the high demand for new residential housing development from the retirement and vacation home markets. All three interact to determine that the value of land per farm is relatively low compared to the large industrialized operations in the eastern portions of the state, despite relatively high per acre land values resulting from its disproportionate scarcity.

At the center of this bid-rent function is the reality that with a high per acre cost of land, agriculture must necessarily realize high per acre returns, in order to make agriculture economically justifiable. Data from the USDA's Census of Agriculture indicate that roughly 34 percent of the region's farms reported net losses in 2007. This was up from only 12 percent in 2002. The average inflation adjusted per farm net income gain appears to have fallen by around 22 percent during this period. The state, by comparison, experienced an increase in adjusted per farm net gain of around ten percent. What this indicates is that both the number of farms making a profit from agriculture, and the amount of profit earned, are decreasing.

Available data on farm production costs suggest that hired labor made up roughly 27 percent of the region's total production expenses. Hired farm labor includes individual workers that are hired directly by a farm operator, as opposed to going through a farm labor contractor. Contract labor, by comparison, makes up only around six percent of the region's total operating expenses. Other important expense categories in the region include "Supplies, Repairs, and Maintenance” and "Purchased Feed.” Each of these categories made up around nine percent of total operating expenses. The remainder of the categories range in importance from one to six percent of total costs. Operating expenses at the state level were concentrated differently. Roughly 38 percent of total operating expenses in the state were in the category of "Purchased Feed." This was presumably to support the state's large livestock operations. Likewise, 20 percent of the state's costs are from the purchase and lease of livestock and poultry. Only seven percent of the state's costs are associated with hired labor.

The final factor to call out regarding farm operating expenses is that the total cost of production for farmers in the Land-of-Sky region is roughly \$450 less per acre than in the state as a whole. Based on 2007 census figures, the average cost of farm production in the region was around $\$ 530$ per acre, compared to over $\$ 980$ per acre for the state. This could be an outcome of the difference in commodity mix. Nonetheless, when we compare the average value of crop production per farm to the average per farm production expense, the lower relative profitability of the region's farms can be attributed to both declining average revenues and increasing average cost. 
Shifting gear somewhat, it seemed necessary to highlight two growth sectors that some believe may help overcome the industries' decline. These are organic farming and direct marketing of farm products. Figures on the number of farms and the number of acres participating in organic production suggest that only around 0.4 percent of the region's farmland and 0.5 percent of total farm sales were associated with this type of production. This is compared to 0.1 percent of both farmland and sales for the state as a whole. While this suggests that the region is slightly more specialized in this subsector than the remainder of the state, the practice of organic farming continues to be marginal at best. Nevertheless, as the Asheville metropolitan area continues to grow, this sector may experience increasing demand from discerning urban consumers. Despite a lack of historical data, the general consensus among industry representatives is that organic production is a rapidly growingniche.

While still comprising a relatively small proportion of the industry, the marketing of agricultural products directly to consumers is a uniquely visible and growing aspect of the industry. According to the census figures, nearly 11 percent of the region's farms reported participating in direct marketing in 2007. This was up from 8.6 percent in 2002. Likewise, seven percent of farms statewide reported direct marketing in 2007, up from around six percent in the prior census. This trend is important because it helps to provide revenue directly to farmers, rather than funneling it through intermediaries, like wholesalers. On an average basis, figures suggest that this equated to almost $\$ 9,000$ per participating farm in 2007, up from $\$ 7,600$ in 2002. This suggests that the subsector may play a critical role in bolstering the economics of small scale agriculture, despite relatively low participation rates.

\section{Interview Methodology and Results}

The questions asked of interview participants were semi-structured, designed to explore a core set of themes while being attentive to topics that emerged during one-on-one interviews. Interviews were conducted with farmers, support service providers, and industry leaders between January 15th and March 21st, 2011. Of the 47 individuals and businesses invited to participate, 25 responded to the invitation, and 22 interviews were successfully carried out. Due to the challenges associated with acquiring or compiling a comprehensive list of agricultural producers and support business operators, interview participants were selected using non-probability, snowball sampling. The first participants were agriculture specialists with North Carolina Cooperative Extension. Agricultural producers were targeted in the region's dominant crop categories of fruits, vegetables, nurseries, greenhouses, and livestock (including dairies). Support business operators were targeted in a variety of farm input categories that were indicated to be critical to the continuation of the industry. These included general farm supplies, petro-chemical supplies, heavy equipment dealerships, and farm-labor contractors. Other business owners were also targeted in the post-harvest service categories of commodity processing, packaging, wholesaling, and shipping.

\subsection{Support Service Dependence on Regional Agriculture}

The results of the one-on-one interviews indicated that most agricultural support services would not be critically affected by even major reductions in local agricultural output. Thus, some assortment of support services is likely to remain available to farmers, despite trends of 
farmland conversion and declining production value. Interview participants described two primary reasons for this resilience. The first is that many businesses serve a much wider market area than just the four Land-of-Sky counties. The second is that some businesses serve a highly diversified client base, making them less reliant on farm related spending.

The majority of agricultural support businesses and institutions reported serving a market area that extends well beyond the borders of the four county region. These businesses included petro-chemical suppliers, heavy equipment dealers, and farm-labor contractors, as well as post-harvest processers, packagers, shippers and wholesalers. While the extent of this market area depends on the specific business or industry in question, the most frequent delineation was an area within 200-miles of the City of Asheville. By serving a market area of at least 100-miles, businesses can access the markets of Hickory and Gastonia, North Carolina; Greenville, South Carolina; and Knoxville, Tennessee. Expanding this to 200-miles, businesses can access customers as far south as Atlanta, Georgia, and as far north as Charleston, West Virginia. This increases the number of farms that can be served by support businesses by up to 80 times

The only support business category that notably breaks from this trend is the generic farm supply stores sector. Typically owned and operated by independent entrepreneurs, these businesses are fairly ubiquitous throughout the region, with at least four or five separate establishments in each county. These tend to offer some variation on the same general array of products, including everything from general household items and hardware, to veterinary supplies, fertilizer, and tractor parts. The key to the success of these businesses is a broad customer base located within only five to ten miles. Business owners described their customers as ranging from households with pets, to hobby farmers, to commercial cattle ranchers. While a handful of these businesses may be directly impacted by declining production in any given commodity, the broad appeal and adaptability of these generic farm supply establishments makes them likely to persist.

To illustrate this point, consider the case of one farm supply store in Madison County. As a direct outcome of the tobacco buy-out program, this business lost around 60 to 70 percent of its total sales volume. In response to this structural change, the business now targets more customers in the hobby farming and livestock industries, and carries more veterinary and animal health supplies. Their stock of tobacco related products was almost completely phased out. This change in client base has allowed the business to recoup roughly 40 percent of its lost business. As the organic market continues to grow, this business anticipates taking advantage of growing diversification in the region's commodity mix by expanding its supply of organic products to include more natural pesticides and non-GMO seeds.

\subsection{Support Services At-Risk of Closure or Relocation}

Despite the resilience of most support businesses in the region, interview participants described two service industries that may be at-risk. These included regional stockyard and auction facilities, and heavy equipment and tractor dealerships. Industry representatives also showed concern over the future availability of agricultural extension services, but for altogether different reasons. 


\subsubsection{Regional Stockyard and Auction Facilities}

As of 2007, the livestock industry accounted for roughly 20 percent of regional farm output. The majority of the livestock operations in the region are oriented toward the production of stocker cattle. These are primarily cows and fat calves that are grass-fed for three to five-months, prior to being shipped to industrialized feedlots in the Midwest. Grass-fed cattle are somewhat less prominent as a source of meat production since reliance on this feedstock results in relatively less robust marbling and steaks cut from these animals typically sell at lower prices. Once the cattle arrive on Midwestern farms, they are fed using that region's vast supplies of corn and other feed grains.

Because the industry is highly oriented toward stocker cattle that are sold to Midwestern buyers, the presence of a forum for the sale of these animals is highly important to the success of local ranchers. Stockyards, in the context of regional cattle raising, are essentially holding areas for livestock awaiting sale, and typically include auction facilities. In 2004 the Asheville Livestock Market closed due presumably to insufficient sales volumes. A similar market opened the following year just across the Buncombe County line in Canton, North Carolina; only to close in 2007. After three years without local access to a stockyard facility, the non-profit organization WNC Communities completed construction on a new stockyard and auction compound in Canton. The three million dollar in capital cost was paid with grant funds from the North Carolina Tobacco Trust Fund Commission, among other sources.

A 2008 market analysis conducted by Agribusiness Solutions provides some useful insights into the potential viability of this new facility. The consultants used a 15 county study area representing the counties from which the facility might be expected to draw customers. The report found that within this relatively large market area, there may be just enough demand to support two stockyard facilities handling around 20,000 head, per facility, per year. There are two complications that make the viability of the new stockyard questionable. The first is that there are upwards of ten existing facilities within a 50 mile radius. Although cattlemen are known to frequent the closest point of sale for their animals, overcoming the existing relationships they have with buyers at other facilities could pose a significant challenge. The second complication is the trend toward declining cattle populations. Interviews indicated that the region has not yet fully recovered from a severe drought that occurred in 2007. With fewer head of cattle being raised for sale, there is a high likelihood that the new facility will face slackening long-term demand. However, given the broad support provided by organizations like WNC Communities, hope remains that the region will continue to develop innovative solutions.

\subsubsection{Heavy Equipment or Tractor Dealerships}

In recent years the region lost most of its heavy equipment dealers. Heavy equipment in this context refers to large horse-power tractors, such as those manufactured by the John Deere, New Holland, and International brands. The main reason given for the loss of these dealerships is the tremendous durability of their products. Tractors have a working lifespan of 30 to 40 years or more, assuming they are being properly maintained. Thus, a farmer may purchase only one or two during their entire farming career. This durability accounts for 
larger short-run elasticities that translate to lower purchase volumes during tight economic times. Thus, as agricultural output contracts, dealerships are forced to either shut down or to rely less heavily on new product sales. One informant noted that over the last two years, sales of new machines have dropped from roughly 60 percent of the dealership's business, to only 30 percent. However, as heavy machinery becomes more computerized, farmers are less able to maintain their equipment without the assistance of trained mechanics, but are reluctant to take on the added costs of dealer based maintenance and servicing.

One of the more interesting reasons given for the closure of the Asheville John Deere dealership was a decision made at the corporate level to sell John Deere brand lawnmowers and domestic-use machinery through big box retailers, like Lowe's and Home Depot. This significantly reduced the overhead costs associated with the sale of these lawn and garden products. However, it also cannibalized one of the supportive revenue streams from their farm oriented dealerships. Also implicit in the dealership closure is the reality that the region may have insufficient farming activity to support a full size dealership under this new sales model.

One other important trend in farm equipment sales is the proliferation of second hand equipment. As the larger operations in the Midwest upgrade and discard their machines, these tractors, combines and other pieces of large equipment are resold through various networks to farmers throughout the United States and Mexico. Interview participants commented on farmers going to Iowa to purchase commercial farm equipment, taking on the cost to ship these products to their home operations. Note that although these products are used, they often require little in terms of retrofitting or reconditioning. This secondary market plays an important role in ensuring the availability of farm equipment for smaller scale producers, who may not have the need or capacity to purchase new industrial scale implements.

\subsubsection{Agricultural Extension and Research Services}

The national cooperative extension network is designed to leverage the national land-grant university system, to provide research and education services to the agricultural community regarding the biological, economic, and social aspects of farming. Located in the West District of the North Carolina Cooperative Extension division, the Land-of-Sky region boasts some unique resources, including the Mountain Horticultural Crops Research and Extension Center (MHCREC) in Mills River. Despite the presence of these unique and valuable resources, both farmers and support service providers expressed concern that cuts in federal and state funding might threaten the future availability of these crucial assets. Although only indirectly associated with of the volume agricultural production, the potential loss could be devastating.

To illustrate their concern, most farmers described the terrible blight that affected the region's tomato growers as recently as 2009. They commented how the staff at the MHCREC played an important role in developing new strains of plants resistant to the offending disease. It was made clear that if not properly and promptly addressed, factors like disease and climate change may still hold the potential to bring about the collapse of the industry. Because the region relies on an atypical mix of fruit, vegetable, nursery, greenhouse, and livestock 
products, the national research institutions focused on grain and oilseed commodities may be less prepared to solve the region's issues. Thus, if region specific agricultural research and extension services become unavailable, or if they are critically stunted due to state and federal budget cuts, the region may be abnormally susceptible to the effects of biological and environmental change. The farmers and support service providers interviewed repeatedly expressed a desire to see continued local government support for farm extension services. Some went as far as to suggest that local governments should begin actively recruiting businesses that could provide ancillary benefits to the local farm community in this regard. Seed breeders, for example, could offer the unique benefit of selling valuable commercial products while also providing critical expertise necessary to overcome issues of disease and drought.

\section{Estimated Economic Impacts}

Beyond simply establishing the existence of a critical mass threshold, this research sought to evaluate the likely economic impact of changes in agricultural output, combined with anticipated changes in support service availability. This was done using the IMPLAN 3.0 input-output modeling software, the industry standard for economic impact analysis. While this tool leverages a robust dataset of regional economic accounts, the model assumes that the production function for each industry is linear and homogeneous. This implies that an industry's purchase and supply behavior is directly proportional the level of output in that industry. This assumption limits the model's ability to account for structural changes in an industry or economy. Nevertheless, by incorporating knowledge gained through qualitative interviews, assumptions and inputs were developed to account for some of the unique industry interactions that may not normally be captured. For example, we know that a severe decline in farm output may result in the loss of certain support services, like heavy equipment dealerships. Thus, we can incorporate this structural shift as a decrease in output within certain industries, like the Wholesale Trade sector.

\subsection{Impact Specification}

\subsubsection{Specifying Scenarios}

Because project stakeholders expressed interest in understanding the impacts of changes in agricultural output and changes in support service availability, the events are broken down into multiple scenarios. These include a base-case scenario that incorporates projected changes in farm output, and two alternative scenarios that include potential changes in support service availability. 


\section{Table 2: Changes in Regional Output for use in IMPLAN}

\begin{tabular}{|c|c|c|c|c|c|}
\hline \multicolumn{6}{|l|}{ Base Case Scenario } \\
\hline Industry Sector & $\begin{array}{l}\text { IMPLAN } \\
\text { Sector }\end{array}$ & $\begin{array}{l}\text { NAICS } \\
\text { Sectors }\end{array}$ & $\begin{array}{c}\text { Default } \\
\text { RPCs (a) }\end{array}$ & $\begin{array}{l}2010 \text { Proj. } \\
\text { Ind. Output } \\
(\$, 000)(b)\end{array}$ & $\begin{array}{c}\text { Est. 3-Year } \\
\text { Change } \\
(\$, 000)(\mathrm{c}) \\
\end{array}$ \\
\hline Vegetable and Melon Farming & 3 & 1112 & $67.4 \%$ & $\$ 21,098$ & $(\$ 3,568)$ \\
\hline Fruit Farming & 4 & $\begin{array}{l}11131,11132,11133 \\
11134,11135\end{array}$ & $0.1 \%$ & $\$ 21,075$ & $(\$ 3,564)$ \\
\hline Greenhouse and Nursery Farming & 6 & 1114 & $77.8 \%$ & $\$ 87,683$ & $(\$ 14,828)$ \\
\hline Cattle Ranching and Farming & 11 & $11211,11212,11213$ & $48.4 \%$ & $\$ 8,492$ & $(\$ 1,293)$ \\
\hline Dairy Cattle and Milk Production & 12 & 11212 & $19.7 \%$ & $\$ 11,683$ & $(\$ 1,779)$ \\
\hline
\end{tabular}

\begin{tabular}{|c|c|c|c|c|c|}
\hline \multicolumn{6}{|l|}{ Alternative Scenario 1} \\
\hline Industry Sector & $\begin{array}{l}\text { IMPLAN } \\
\text { Sector }\end{array}$ & $\begin{array}{l}\text { NAICS } \\
\text { Sectors }\end{array}$ & $\begin{array}{l}\text { Default } \\
\text { RPCs (a) }\end{array}$ & $\begin{array}{l}2010 \text { Proj. } \\
\text { Ind. Output } \\
(\$, 000)(b)\end{array}$ & $\begin{array}{l}\text { Est. 3-Year } \\
\text { Change } \\
(\$, 000)(d)\end{array}$ \\
\hline Wholesale Trade & 319 & 42 & $63.2 \%$ & $\$ 813,975$ & - \\
\hline Farm Machinery Wholesalers (e) & 319 & 423820 & $63.2 \%$ & $\$ 11,440$ & $(\$ 5,720)$ \\
\hline
\end{tabular}

\begin{tabular}{|c|c|c|c|c|c|}
\hline \\
\hline & \multirow{2}{*}{$\begin{array}{l}\text { IMPLAN } \\
\text { Sector } \\
319\end{array}$} & $\begin{array}{l}\text { NAICS } \\
\text { Sectors }\end{array}$ & $\begin{array}{l}\text { Default } \\
\text { RPCs (a) }\end{array}$ & $\begin{array}{l}2010 \text { Proj. } \\
\text { Ind. Output } \\
(\$, 000)(b)\end{array}$ & $\begin{array}{c}\text { Est. 3-Year } \\
\text { Change } \\
(\$, 000)(f)\end{array}$ \\
\hline $\begin{array}{l}\text { Alternative Scenario } 2 \\
\text { Industry Sector } \\
\text { Wholesale Trade }\end{array}$ & & 42 & $63.2 \%$ & $\$ 813,975$ & \\
\hline $\begin{array}{l}\text { Wholesale Trade } \\
\text { Farm Machinery Wholesalers (e) }\end{array}$ & 319 & 423820 & $63.2 \%$ & $\$ 11,440$ & $(\$ 11,440)$ \\
\hline
\end{tabular}

Notes:
(a) Default Regional Purchase Coefficients or RPCs are are those defined by the IMPLAN social account matrices.
(b) Due to data suppression for detailed commodity categories, 2007 sales figures are derived using the 2002 proportional distribution of sales by commodity and 2007 total sales values.
(c) Projected changes in total sales figures are estimated using the compound annual growth rate for primary commodity category between inflation adjusted 2002 sales values and 2007 sales values.
(d) Scenario 1 involves a 50 percent decrease in output in the Farm Marchinery Wholesalers (NAICS 423820) subsector of the Wholesale Trade sector (NAICS 42).
(e) Values for the Farm Machinery Merchant Wholesale (NAICS 423820) subsector of the Wholesale Trade (NAICS 42) sector are calculated based on the proportion of total employment in the Wholesale Trade sector that is attributable to the Farm Machinery Wholesale subsector.
(f) Scenario 2 includes a 100 percent decrease in output in the Farm Machinery Wholesalers (NAICS 423820) subsector of the Wholesale Trade Sector (NAICS 42).

Sources: USDA, 2011; Minnesota IMPLAN Group, 2007.

Table 2 illustrates this breakdown in more detail. The base-case scenario assumes that the total dollar value of agricultural output in the region would decline at a constant compound annual rate equal to that experienced between 2002 and 2007. In order to ensure that the compound annual rate of changed used to develop projections of farm output was the most reflective of current economic conditions, as well as historic trends, this analysis considered both the ten-year rate of change for the period from 1997 to 2007 and the five-year rate of change for the period from 2002 to 2007. Examining that the inflation adjusted total crop value estimates identified a real increase in total crop values between 1997 and 2002, followed by a dramatic drop between 2002 and 2007. Ultimately, the higher five-year rate of 
change was determined to be more reflective of current economic conditions. This rate was calculated using inflation adjusted 2007 dollars and distinguishes between livestock, and non-livestock commodities.

As a simplifying assumption, this portion of the analysis includes only the most dominant crop types identified earlier. Translated into IMPLAN industry sectors, these include Vegetable and Melon Farming, Fruit Farming, Greenhouse and Nursery Farming, Cattle Ranching and Farming, and Dairy Cattle and Milk Production. Because this analysis is interested in better understanding how ongoing trends may impact the economy in the future, the base-case events are modeled to occur over a three-year period, beginning in 2011. The three-year timeframe is used to accommodate the fact that the potential support service impacts modeled in the alternative scenarios are not likely to occur all at once, but gradually over time.

The two alternative scenarios are intended to model the potential impacts of changes in support service availability. Interviews determined that the most likely support service categories to be impacted by a loss of critical mass in regional farm output are heavy equipment dealerships and stockyards. Because the only stockyard facility in western North Carolina is located outside of the Land-of-Sky region, it is not possible to model the loss of this facility as a regional economic event. Thus, the only alternative scenario event that can be modeled is the potential loss of the regions heavy equipment dealerships. To test the sensitivity of the economy to changes in output from this sector, Alternative Scenario 1 assumes only a 50 percent reduction in the total value of output from the farm machinery subsector, over the three-year model timeframe. Alternative Scenario 2 assumes a 100 percent reduction.

One additional complication identified when specifying the alternative scenario impacts was that IMPLAN does not provide an industry sector unique to heavy equipment or farm machinery dealerships. Using North American Industry Classification System (NAICS) codes, heavy equipment dealerships are classified as Farm and Garden Machinery and Equipment Merchant Wholesalers (NAICS 423820) under the Wholesale Trade sector (NAICS 42). The IMPLAN software only offers a code for the Wholesale Trade sector (IMPLAN 319) in its entirety. While it is possible to define a custom industry code, doing so would be beyond the capacity of this research project. Thus, industry output values used to define the events in the alternative scenarios were estimated using the subsector's proportion of total employment in the Wholesale Trade sector. Employment in the Farm Machinery subsector accounted for only 1.4 percent of total employment in the Wholesale Trade sector in 2007. Impacts are then estimated based on industry relationships for Wholesale Trade sector as a whole. 


\subsection{Estimated Economic Effect}

\section{Table 3: Regional Economic Impacts, IMPLAN 3-Year Estimates}

\begin{tabular}{|c|c|c|c|c|}
\hline \multicolumn{5}{|l|}{ Base Case Scenario } \\
\hline Farm Related Impacts & Direct & Indirect & Induced & Total \\
\hline Employment (Jobs) & (66) & (14) & $(32)$ & (111) \\
\hline Industry Output (a) & $(\$ 6,129,255)$ & $(\$ 1,512,423)$ & $(\$ 3,261,995)$ & $(\$ 10,903,673)$ \\
\hline
\end{tabular}

\begin{tabular}{|c|c|c|c|c|}
\hline \multicolumn{5}{|l|}{ Alternative Scenario 1} \\
\hline Industry Related Impacts & Direct & Indirect & Induced & Total \\
\hline Employment (Jobs) & $(26)$ & $(10)$ & (12) & (48) \\
\hline Industry Output (a) & $(\$ 3,563,279)$ & $(\$ 1,001,271)$ & $(\$ 1,296,171)$ & $(\$ 5,860,721)$ \\
\hline \multicolumn{5}{|l|}{ Cumulative Impacts (b) } \\
\hline Employment (Jobs) & (92) & (24) & (44) & (159) \\
\hline Industry Output (a) & $(\$ 9,692,534)$ & $(\$ 2,513,694)$ & $(\$ 4,558,166)$ & $(\$ 16,764,394)$ \\
\hline
\end{tabular}

\begin{tabular}{|c|c|c|c|c|}
\hline \multicolumn{5}{|l|}{ Alternative Scenario 2} \\
\hline Industry Related Impacts & Direct & Indirect & Induced & Total \\
\hline Employment (Jobs) & $(52)$ & (20) & $(25)$ & (97) \\
\hline Industry Output (a) & $(\$ 7,126,558)$ & $(\$ 2,002,543)$ & $(\$ 2,592,341)$ & $(\$ 11,721,442)$ \\
\hline
\end{tabular}

Cumulative Impacts (b)

$\begin{array}{lrrrrr} & (118) & (33) & (56) & (207) \\ \text { Industry Output }(a) & (\$ 13,255,813) & (\$ 3,514,966) & (\$ 5,854,336) & (\$ 22,625,115)\end{array}$

Notes:
(a) Dollar figures given in 2007 dollars.
(b) Includes the cumulative impacts of the modeled changes in regional farm output, combined with the industry specific impacts from the alternative scenario.

Sources: USDA, 2011; Minnesota IMPLAN Group, 2007.

Table 3 reports the total estimated direct, indirect, and induced economic impacts of the base-case and two alternative scenarios. Reported impacts include industry output (the dollar value of goods produced) and employment (jobs in the region). For the base-case scenario, the direct impacts are equal roughly $\$ 6.1$ million and 66 jobs. The indirect effect of this decline in regional farm output on related industries is estimated to equal more than $\$ 1.5$ million in lost output and roughly 14 jobs. The majority of the indirect effects appear in industries that provide packing supplies for farm products. The induced effects are those caused by changes in household spending and are estimated to be even greater than the indirect effects at nearly 3.3 million dollars, including a loss of 32 jobs. Cumulatively, the total economic impact of the projected three-year decline in regional farm output is estimated to equal a loss of over $\$ 10.9$ million in regional output and over 110 jobs.

The initial impact of Alternative Scenario 1 assumes a 50 percent decrease in the total output of the farm machinery wholesaling subsector. The direct effect of this decrease is estimated to 
equal a loss of \$3.6 million in total output and approximately 26 jobs. The indirect effect on related industries is estimated at just over $\$ 1.0$ million dollars in total output and 10 jobs. The induced effect is equal a loss of over $\$ 1.3$ million and 12 jobs. Combined, the direct, indirect, and induced effects equal a total combined impact of \$5.9 million in lost regional output and 48 jobs over three years. Considered cumulatively with the base-case scenario impacts, the total economic effect is estimated to be approximately equal to a $\$ 16.8$ million loss in regional output and almost 160 jobs over three years.

As noted earlier, Alternative Scenario 2 assumes a complete loss of output from the farm machinery wholesaling subsector. The direct effect of which is estimated to equal a loss of $\$ 7.1$ million in industry output and over 50 jobs. The indirect effect of this forfeiture is estimated as a $\$ 2.0$ million loss in related industry output with an additional 20 jobs being phased out over three years. The induced loss in regional output due to changes in household spending is estimated to equal almost \$2.6 million with a loss of around 25 jobs. Combined, the complete loss of the farm machinery wholesaling subsector is estimated to equal a loss of regional output equal to \$11.7 million and nearly 100 jobs over three years. When including the base-case scenario the cumulative totals increases this total impact to a loss of nearly 22.6 million and over 200 jobs.

\section{Summary and Conclusions}

The intent of this research was to consider the existence of a critical mass threshold in agricultural production, below which crucial support services could be expected to close down or relocate outside the region. Much of the evidence collected through qualitative interviews suggests that for most support service businesses, no such critical mass threshold exists at the regional level. Thus, as local agricultural output continues to decline (as is implied by the available statistics), farmers may expect the continued availability of most farm production inputs and support services, if at some distance or additional cost. Thus doubt still remains whether a decline in agricultural output throughout the greater American Southeast could eventually precipitate the loss of critical support services throughout a much wider area. It is no secret that urbanization, as well as environmental and economic change, are threatening the viability of agricultural producers throughout the country. Additional research may be necessary to identify exactly how susceptible the region may be to this eventuality.

This research also sought to identify which support service types might yet be most at-risk. Although a majority of support businesses are not tremendously reliant on regional output, interviews identified three sectors that may be conceivably threatened with reduced availability. Though the risks associated with loosing these services may include substantial economic loss - as evidenced by the economic model - existing achievements like those of WNC Communities suggest that the region may be able to overcome these challenges through the deployment of innovative business models. In the heavy equipment wholesaling sector, for example, promotion of secondary market networks may help ensure the local availability of farm implements and products. For farm extension services, continued coordination between industry leaders, local government representatives, and farm extension 
service providers may help guarantee continued state and federal funding. In these ways regional actors can prevent the sizable economic implications of a loss of output and employment in these critical service sectors; as well as the inevitable impacts that the loss of these services might have on farmers themselves.

This last point prompts acknowledgment that it is the decline in regional agricultural output and profitability that is the real issue. The loss of support services would only serve to exacerbate existing trends. Because this research focused exclusively on the future availability of support services given declining regional output, additional attention should be given to how farmers would be impacted by such a loss of service availability. Lastly, significant attention should be given to the causes of the economic decline of the region's agriculture. While urbanization is a known influence, other factors such as an unusual commodity mix may play a pivotal role.

\section{Acknowledgement}

The research was originally performed by Aaron J. Nousaine as Master's Project in partial fulfilment of the requirements for a Master of City and Regional Planning from the University of North Carolina at Chapel Hill. Mr. Nousaine would like to thank his faculty advisors for comments on earlier versions of this work. The UNC Center for Competitive Economies assisted in providing additional data to develop this article in present form. The authors also wish to thank Pamela Schore, Knowledge Management Librarian at the UNC Kenan Institute of Private Enterprise for her assistance with GIS mapping.

\section{References}

Agribusiness Solutions. (2008). Market Analysis of a Potential Livestock Auction Market in Western North Carolina. Waynesville, NC: Haywood County Economic Development Commission.

Esseks, D., Oberholtzer, L., Clancy, K., Lapping, K., \& Zurbrugg, A. (2009). Sustaining Agriculture in Urbanizing Counties: Insights From 15 Coordinated Case Studies. Lincoln, NE: University of Nebraska.

Hendrickson, M., Heffernan, W., Howard, P., \& Heffernan, J. (2001). Consolidation in Food Retailing and Dairy: Implications for Farmers and Consumers in a Global Food System. British Food Journal, 103, 715-728. http://dx.doi.org/10.1108/00070700110696742

Hoppe, R, \& Banker, D. (2010). Structure and Finances of U.S. Farms: Family Farm Report, 2010 Edition. U.S. Department of Agriculture Economic Information Bulletin, 66.

Hoppe, R., MacDonald, J., \& Korb, P. (2010). Small Farms in the United States: Persistence Under Pressure. U.S. Department of Agriculture Economic Information Bulletin, 63.

Lapping, M. (1982). Toward a Working Rural Landscape. In C. Reidel (Ed.), New England Prospects. Hanover, NH: University Press of New England.

Lynch, L., \& Carpenter, J. (2002). Is a Critical Mass of Agricultural Land Needed to Sustain an Agricultural Economy? College Park, MD: Center for Agricultural and Natural Resource 


\section{Macrothink}

Policy.

Lynch, L., \& Carpenter, J. (2003). Is There Evidence of a Critical Mass in the Mid-Atlantic Agriculture Sector Between 1949 and 1997? Agricultural and Resource Economics Review, 31, 116-128.

McDonald, J., Hoppe, R., \& Banker, D. (2006). Growing Farm Size and the Distribution of Farm Payments. U.S. Department of Agriculture Economic Information Bulletin, 06.

Perrett, A. (2007). The Infrastructure of Food Procurement and Distribution: Implications for Farmers in Western North Carolina. Asheville, NC: Appalachian Sustainable Agriculture Project.

Porter, M. E. (1998). Clusters and the new economics of competition. Boston: Harvard Business Review.

Porter, M. E. (2000). Location, competition, and economic development: Local clusters in a global economy. Economic development quarterly, 14(1), 15-34. http://dx.doi.org/10.1177/089124240001400105

Porter, M. (2003). The economic performance of regions. Regional studies, 37(6-7), 545-546. http://dx.doi.org/10.1080/0034340032000108688

Stull, D., \& Broadway, J. (2004). Slaughterhouse Blues: The Meat and Poultry Industry in North America. Belmont, CA: Thomson Wadsworth.

U.S. Department of Agriculture. (2009). Summary Report: 2007 National Resources Inventory. Washington, DC: National Resources Conservation Services.

\section{Copyright Disclaimer}

Copyright reserved by the author(s).

This article is an open-access article distributed under the terms and conditions of the Creative Commons Attribution license (http://creativecommons.org/licenses/by/3.0/). 